\title{
High magnitude mixed astigmatism correction with excimer laser surgery
}

\author{
Correção de astigmatismo misto de alta magnitude \\ com excimer laser em dois tempos cirúrgicos
}

Romero Henrique Carvalho Bertrand' ${ }^{1}$, Adriana Leite Xavier Bertrand ${ }^{1}$, Antônio Augusto Velasco e Cruz²

\begin{abstract}
High astigmatism correction represents a challenge for the refractive surgeon with current available technology. Excimer laser correction should be considered as an option in the available therapeutic arsenal. We report a patient with astigmatism higher than eight diopters to whom it was used a treatment with LASIK (Laser Assisted In Situ Keratomileusis) in two surgical moments, using a new generation of excimer laser with an optimized aspheric profile.
\end{abstract}

Keywords: Astigmatism/surgery; Keratomileusis, laser in situ ; Case reports

\section{RESUMO}

O alto astigmatismo representa um desafio para o cirurgião refrativo devido à limitação da tecnologia atualmente disponível. A correção com excimer laser deve ser considerada uma opção no arsenal terapêutico disponível. Apresentamos um paciente com astigmatismo superior a 8 dioptrias que realizaou um tratamento com a técnica LASIK (Laser Assisted in Situ Keratomileusis) em dois tempos cirúrgicos, utilizando uma nova geração de excimer laser com perfil asférico otimizado.

Descritores: Astigmatismo/cirurgia; Ceratomieleuse assistida por Excimer laser in situ; Relatos de caso

\footnotetext{
1 Federal University of Maranhão, São Luis/MA, Brazil.

2 Ribeirão Preto Medical School, São Paulo University, Ribeirão Preto/SP, Brazil.
}

The authors declare no conflict of interest.

Received for publication 21/04/2013 - Accepted for publication 14/04/2014. 


\section{INTRODUCTION}

$\mathbf{R}$ egular astigmatism leads to image formation in two per pendicular planes, with two different foci, producing image distortion, shades, or even diplopia.The greater its magnitude, the greater the loss in visual quality and the chance of such symptoms. In mixed astigmatism, for example, image formation occurs in two axes, one anterior and one posterior to the retina. ${ }^{(1,2)}$

Visual correction of astigmatism can be achieved using glasses, contact lenses, refractive surgery with excimer laser, intrastromal corneal ring implants (in specific cases, especially in irregular astigmatism secondary to corneal ectasia), intraocular lenses (in patients with concomitant cataract), and even corneal transplantation (in patients who cannot undergo other treatments, e.g. those with severe corneal ectasia). ${ }^{(1)}$ Each case should be assessed in detail and correctly diagnosed before performing any procedure. ${ }^{(3)}$

We report on a patient with high astigmatism, a condition that is uncommon in clinical practice and whose characteristics often hinder a safe and adequate ablation.

\section{Case Report}

Male, 32-year-old patient working as a construction foreman, wishing to correct his refractive error.He reported low vision with glasses and intolerance to contact lenses.He had not used any type of visual correction for 5 years.

Ophthalmic examination found an uncorrected visual acuity of 20/200 in both eyes and a corrected visual acuity (CVA) of 20/80 in the right eye (RE) and partial 20/50 in the left eye (LE).Static and dynamic refraction were identical (RE:+2.00 $9.00 \mathrm{X} 10^{\circ}$; LE: $+1.50-8.00 \times 175^{\circ}$ ). Tomography of the cornea and anterior segment with aPentacam ${ }^{\mathrm{TM}}$ device (OCULUS Optikgeraete GmbH, Wetzlar, Germany), showed anterior corneal astigmatism of 8.3 dioptres in the RE and 7.2 dioptres in the LE(Figures 1 and 2). A detailed clinical examination found no abnormalities in both eyes.

Since the patient had regular astigmatism with no signs of corneal ectasia or other eye conditions, correction withexcimer laser refractive surgery was suggested.There was, however, a technical limitation, as the maximum cylindrical correction with the available equipment, a Schwind Amaris ${ }^{\mathrm{TM}}$ device (Schwind $\mathrm{GmbH} \& \mathrm{Co}$, Kleinostheim, Germany), is seven dioptres.

It was thus decided that correction of the cylindrical error would be done in two steps with a minimum interval of three months between them. The first procedure aimed fora correction of $+2.50-7.00 \times 10^{\circ}$ in the RE and +2.00-7.00 X $175^{\circ}$ in the LE, with an optical zone of $6.7 \mathrm{~mm}$ for both eyes.

The first LASIK procedure was performed on February $25^{\text {th }}, 2011$ using a Moria M2 ${ }^{\mathrm{TM}}$ (Moria SA, Antony, France) automated microkeratome, and the flap was created with a 130ìm steel blade. The residual bed after the first procedure was estimated at 352ìm for the RE and 389ìm for the LE.

Three months after the first procedure,static refraction was $+0.50-4.00 \times 10^{\circ}$ in the RE and $-0.50-2.00 \times 160^{\circ}$ in the LE, with both eyes showing a CVA of 20/30p. Atomography of the cornea and anterior segment using a Pentacam ${ }^{\mathrm{TM}}$ device (Figures 3 and 4) showed anterior corneal astigmatism of 4.2 dioptres in the RE and 1.9 dioptres in the LE.Central pachymetry was 498 ìm in the RE and 487ìm in the LE.
The second procedure was performed on July $1^{\text {st }}, 2011$. The flap was lifted manually with a surgical spatula.The Schwind Amaris ${ }^{\mathrm{TM}}$ device was programmed for a correction of $+1.00-4.00$ $\mathrm{X} 10^{\circ}$ in the RE and $+0.25-2.50 \mathrm{X} 165^{\circ}$ in the LE using the same method (aberration-free) as in the previous procedure. The optical zone was $6.7 \mathrm{~mm}$ in both eyes. The residual bed after the second procedure was estimated at $331 \mathrm{im}$ in the RE and $305 \mathrm{ìm}$ in the LE.

Manifest refraction one month after the procedure was $0.50-0.50 \times 0^{\circ}$ in the RE and $-0.50-0.50 \times 170^{\circ}$ in the LE, with a CVA of 20/25p in both eyes.Refraction under cycloplegia on February $27^{\text {th }}, 2012$, i.e.one year after the first procedure, was $0.50 \mathrm{X} 0^{\circ}$ in the RE and $-0.50 \mathrm{X} 170^{\circ}$ in the LE, with a CVA of $20 / 25$ in both eyes. In the last follow-up visit on April $17^{\text {th }}, 2013$ refraction values remained stable.

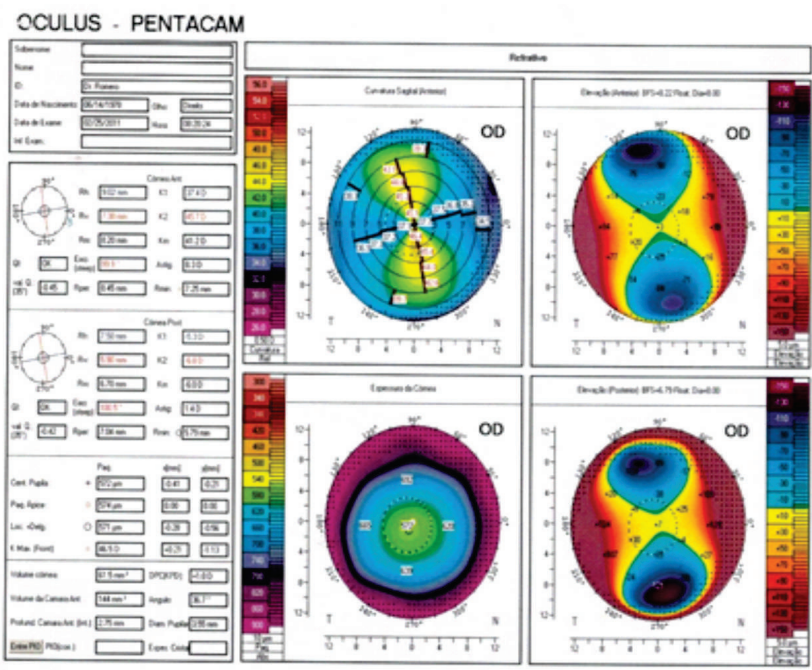

Figure 1: Preoperative tomography of the RE (composite elevation map of the anterior, posterior, sagittal curvature, and thickness of the cornea).

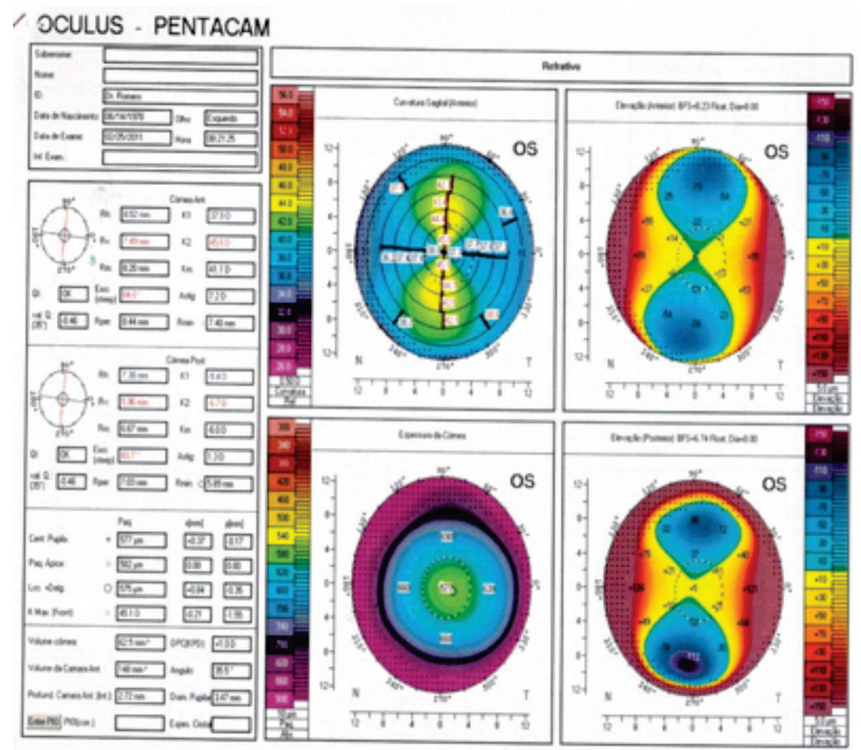

Figure 2: . Preoperative tomography of the LE (composite elevation map of the anterior, posterior, sagittal curvature, and thickness of the cornea). 


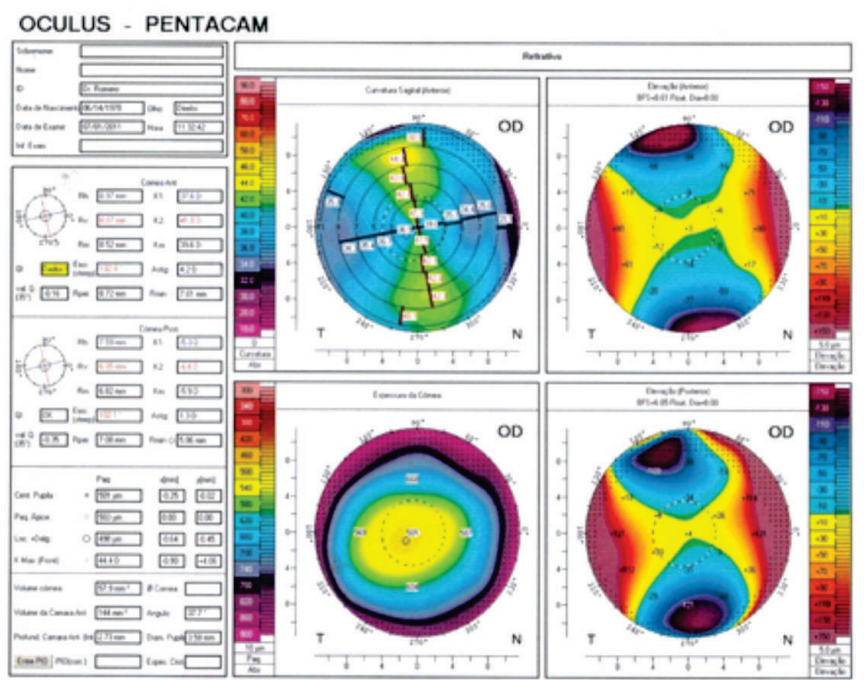

Figure 3: Postoperative tomography of the RE (composite elevation map of the anterior, posterior, sagittal curvature, and thickness of the cornea).

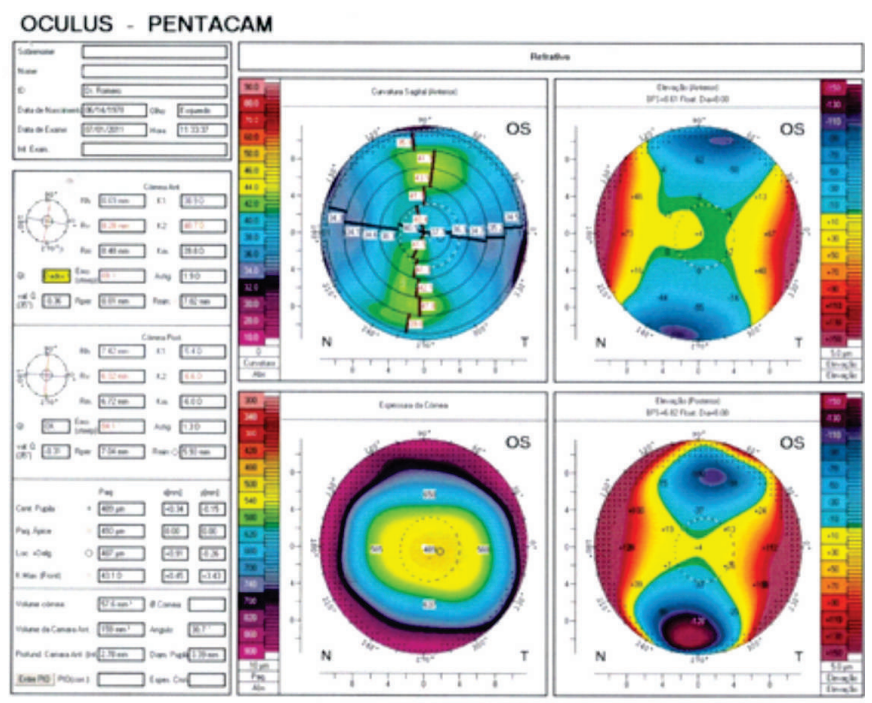

Figure 4: Postoperative tomography of the LE (composite elevation map of the anterior, posterior, sagittal curvature, and thickness of the cornea).

\section{Discussion}

Astigmatism greater than six dioptres is uncommon in clinical practice.

Despite advances, surgical correction of high refractive errors still faces technical limitations. ${ }^{(4-5)}$

Arbelaez and Vidal suggest that improvement in lines of visual acuity can occur in up to one third of operated patients, with good correction of cylindrical components greater than 2 dioptres using Schwind Amaris ${ }^{(6)}$ and Alegretto WaveLight lasers. ${ }^{(7)}$

In the case reported here there was improvement of more than 3 lines of visual acuity in the right eye and 2 lines in the left eye. Both surgical procedures led to significant improvement in spherical and cylindrical components, which is not the general rule in similar cases ${ }^{(8)}$. For example, Igarashi et al. have shown a greater regressionin spherical components and a greater stability in cylindrical components ${ }^{(9)}$.

There are also studies showing astigmatism correction of 3 to 5 cylindrical dioptres (Dcyl) using Visumax femtosecond laserand MEL-80 excimer laser, but with an undercorrection of $1.17 \pm 0.81 \mathrm{D}^{(10)}$.

Chiselipã et al. have shown that in the correction of high astigmatism there is no significant induction of higher-order aberrations. ${ }^{(7)}$ This is particularly the case for optimised aspheric methods with cyclotorsion control.(11) Aslanides stresses that using cyclotorsion correction or compensation leads to better outcomes than when these are not used. ${ }^{(12)}$ Brunson states that when there is an increase in the number of higher-order aberrations greater than $0.35 \mathrm{im}$,wavefront-guided treatment is a better option. ${ }^{(13)}$ In the case reported here, we opted for optimised aspheric treatment with cyclotorsion control, as this seemed to be the best surgical approach for our patient.

According to the literature, LASIK treatment can be performed safely when the astigmatism is located on the anterior surface of the cornea, with correction being significantly higher compared to posterior astigmatism. ${ }^{(14)}$

This report illustrates an alternative approach in the surgical correction of a high cylindrical error using two consecutive procedures, sincecorrection of the total error was not possible using the available technology.

\section{References}

1. Jonh FD, Stephen GS. Treatment of astigmatism. In: Buratto L, Brint S. Custom lasik: surgical techniques and complications. New Jersey: Slack Incorporated;2003.

2. Oliveira C, Castro R, Balby I. Alternativas para correção cirúrgica do astigmatismo. In: Alves MR, ChamonW, NoséW. Cirurgia refrativa. $2^{\text {nd }}$ ed. Rio de Janeiro: Cultura Médica;2007.

3. Gauthier L. [Astigmatism correction with Excimer laser]. J Fr Ophtalmol. 2012;35(3):206-11. Review. French.

4. Kuo IC. Trends in refractive surgery at an academic center: 20072009. BMC Ophthalmol. 2011;11:11.

5. Lukenda A, Martinoviæ ZK, Kalauz M. Excimer laser correction of hyperopia, hyperopic and mixed astigmatism: past, present, and future. ActaClin Croat. 2012;51(2):299-304.

6. Arbelaez MC, Vidal C, Arba-Mosquera S. Excimer laser correction of moderate to high astigmatism with a non-wavefront-guided aberration-free ablation profile: Six-month results. J Cataract Refract Surg. 2009;35(10):1789-98.

7. Chiselipã D, Cantemir A, Stogrea A. [Laser refractive surgery for moderate or high myopic astigmatism-1 year outcome]. Oftalmologia. 2012;56(1):77-85. Romanian.

8. Alio JL, Pachkoria K, El Aswad A, Plaza-Puche AB. Laser-assisted in situ keratomileusis in high mixed astigmatism with optimized, fast-repetition and cyclotorsion control excimer laser. Am J Ophthalmol. 2013;155(5):829-36.

9. Igarashi A, Kamiya K, Shimizu K, Komatsu M. Time course of refractive and corneal astigmatism after laser in situ keratomileusis for moderate to high astigmatism. J Cataract Refract Surg. 2012;38(8):1408-13.

10. Ivarsen A, Næser K, Hjortdal J. Laser in situ keratomileusis for high astigmatism in myopic and hyperopic eyes. $\mathrm{J}$ Cataract Refract Surg. 2013;39(1):74-80.

11. Alió JL, Plaza-Puche AB, Martinez LM, Torky M, Brenner LF. Laser in situ keratomileusis using optimized aspheric profiles and cyclotorsion control to treat compound myopic astigmatism with high cylinder. J Cataract Refract Surg. 2013;39(1):28-35. 
12. Aslanides IM, Toliou G, Padroni S, ArbaMosquera S, Kolli S. The effect of static cyclotorsion compensation on refractive and visual outcomes using the Schwind Amaris laser platform for the correction of high astigmatism. Cont Lens Anterior Eye. 2011;34(3):114-20.

13. Brunson PB, Mann PM. Case report: the correction of a high magnitude of astigmatism with laser-assisted in situ keratomileusis. Optometry. 2011;82(10):614-21.

14. Kugler L, Cohen I, Haddad W, Wang MX. Efficacy of laser in situ keratomileusis in correcting anterior and non-anterior corneal astigmatism: comparative study. J Cataract Refract Surg. 2010;36(10):1745-52.

\section{Corresponding author:}

Romero Henrique Carvalho Bertrand

Av, Sambaquis qd 15 casa 01, Calhau, São Luis/MA, Brazil,

CEP: 65071-390

Tel.: +559891121896

E-mail: romerobertrand@uol.com.br 